\title{
Participación es inclusión: El derecho a la participación política de personas con discapacidad
}

\author{
Renato Antonio Constantino Caycho \\ Priscilla Denisse Coria Palomino \\ Laura Chinyi Ieong Lau
}

En el presente artículo, los autores desarrollan la importancia de garantizar los derechos de participación política y consulta a personas con discapacidad, como un medio para lograr su inclusión social.

Abogado peruano por la Pontificia Universidad Católica del Perú y estudiante de la maestría en Derechos Humanos de esa casa de estudios. Es predocente del Departamento de Derecho de la misma universidad y docente del curso de Derecho Internacional Humanitario (GRIDIS) de la Pontificia Universidad Católica del Perú. Se desempeña como abogado investigador en la ONG Sociedad y Discapacidad - SODIS.

Estudiante de Pregrado de la Facultad de Derecho de la Pontificia Universidad Católica del Perú. Ex directora de la Comisión de Investigación de la Asociación Civil Internacia. Voluntaria de la Clínica jurídica en Discapacidad y Derechos Humanos de la Pontificia Universidad Católica del Perú. Miembro del Círculo de Derechos Humanos de la Facultad de Derecho de la Pontificia Universidad Católica del Perú.

Estudiante de Pregrado de la Facultad de Derecho de la Pontificia Universidad Católica del Perú. Ex miembro del Círculo de Derechos Humanos de la Facultad de Derecho de la Pontificia Universidad Católica del Perú. Practicante profesional del área legal de la empresa San Fernando. Ex alumna de la Clínica Jurídica en Discapacidad y Derechos Humanos de la Pontificia Universidad Católica del Perú. 


\section{Participación es inclusión: El derecho a la participación política de personas con discapacidad}

\section{Introducción}

Durante mucho tiempo, colectivos minoritarios o no hegemónicos han sido excluidos de la posibilidad de participar en la construcción de las decisiones de la sociedad. Pueblos indígenas, mujeres o personas con discapacidad han sido excluidos a través de diversas vías. La principal de estas vías ha sido la exclusión del derecho al voto durante la historia. En la mayor parte de casos, la situación ha cambiado y prácticamente no se cuestiona el hecho de que todas las personas, superada una valla de edad, tengan derecho a votar y a postular a cargos públicos. No obstante, aún subsisten situaciones que impiden que el ejercicio de esos derechos se traduzca en una efectiva representación de los derechos de estos colectivos en situación de exclusión: las imposibilidades fácticas que impiden la participación políticas de estos colectivos Adicionalmente, es necesario señalar que los colectivos requieren participar en la construcción de políticas para que su visión sea correctamente aplicada.

\section{Un nuevo entendimiento de la discapacidad}

Este trabajo se enmarca en lo que hoy se conoce como modelo social de la discapacidad ${ }^{1}$. Como se ha mencionado, tradicionalmente, se había entendido a la discapacidad como el conjunto de impedimentos físicos, sensoriales o mentales que tenían ciertas personas. Es decir, la discapacidad ponía énfasis en una condición que se encontraba en la persona, y que le impedía realizar determinadas actividades. No obstante, hoy en día se entiende que la discapacidad no es una circunstancia natural sino que se presenta de acuerdo a un espacio social. Es así que en realidad una persona tiene discapacidad en tanto la sociedad lo discapacita a través de barreras².

Este cambio de paradigma se debe a la introducción teórica del modelo social de la discapacidad que alcanza consagración normativa en la Convención sobre los derechos de las Personas con Discapacidad ${ }^{3}$. Como señala la Corte Interamericana de Derechos Humanos, el modelo social entiende que "la discapacidad no se define exclusivamente

1 Palacios, Agustina, El modelo social de discapacidad: orígenes, caracterización y plasmación en la Convención Internacional sobre los Derechos de las Personas con discapacidad, Cinca, Madrid, 2008.

2 Barnes, Colin, "Un chiste malo: crehabilitar a las personas con discapacidad en una sociedad que discapacita?". En: Brogna, Patricia (comp.). Visiones y revisiones de la discapacidad, FCE, México DF, 2009, p. 104.

3 Adoptada el 13 de diciembre de 2006. Entró en vigor para el Perú y el resto de países que ratificaron el tratado el 3 de mayo de 2008. 
Participación es inclusión: El derecho a la participación política de personas con discapacidad

por la presencia de una deficiencia física, mental, intelectual o sensorial, sino que se interrelaciona con las barreras o limitaciones que socialmente existen para que las personas puedan ejercer sus derechos de manera efectiva" ${ }^{\prime 4}$. En ese sentido, podríamos decir que una deficiencia es el no poder caminar, pero la discapacidad solo se presentará cuando ante la "inexistencia de rampas" (barrera), una persona en silla de ruedas no pueda ejercer de manera libre y autónoma su derecho al libre tránsito. Por otro lado, es posible señalar que no poder ver es también una deficiencia pero la discapacidad solo aparecerá si una persona con discapacidad visual no puede acceder a información en formatos alternativos (por ejemplo, texto braille).

El modelo social reemplaza a las concepciones anteriores sobre la discapacidad: el modelo de prescindencia y el modelo médico. El primero de ellos establecía la inutilidad total de la persona con discapacidad por lo cual lo mejor era eliminarlo o apartarlo de la sociedad ${ }^{5}$. La idea de hospitales psiquiátricos en los cuales se confina a personas con discapacidad mental responde a esta concepción. En segundo lugar tenemos el modelo médico que establece que la discapacidad está en la persona por lo cual esta deberá esforzarse en superarla para poder actuar en la sociedad ${ }^{6}$. Frente a estos paradigmas, el modelo social define la discapacidad como la interacción de una deficiencia (la persona no ve, no puede caminar, no oye) y una barrera (ausencia de libros en braille o audiotexto, la ausencia de rampas, o la falta de intérpretes en lengua de señas). De esta manera, la discapacidad surge por las barreras de la sociedad, y es en ella donde se origina. En ese sentido, En ese sentido, toda imposición de una barrera u omisión de acciones para levantarla constituirá una limitación en el acceso y ejercicio de un derecho por parte de las personas con discapacidad, y deberá ser entendida como un acto de discriminación (directa, indirecta o estructural) hacia dicho colectivo ${ }^{7}$. Por ello, en estricto, la definición de discapacidad planteada por el modelo social (y recogido en la CDPD) lleva a la conclusión de que es la discapacidad misma la que debe ser

4 Corte Interamericana de Derechos Humanos. Caso Furlán y Familiares v. Argentina. Excepciones Preliminares, Fondo, Reparaciones y Costas. Sentencia de 31 de agosto de 2012. Serie C 246, pár. 133.

5 Palacios, Agustina, El modelo social de discapacidad: orígenes, caracterización y plasmación en la Convención Internacional sobre los Derechos de las Personas con discapacidad, 2008, Cinca: Madrid, pp. 38-39.

6 Palacios, Agustina, El modelo social de discapacidad: orígenes, caracterización y plasmación en la Convención Internacional sobre los Derechos de las Personas con discapacidad, 2008, Cinca: Madrid, pp. 80-81.

7 Bregaglio, Renata, Alcances del mandato de no discriminación en la Convención sobre los derechos de las personas con discapacidad. En: Bregaglio, Renata y Salmon, Elizabeth (coord.). Nueve conceptos claves para entender la Convención sobre los Derechos de las Personas con Discapacidad, IDEHPUCP, Lima, 2015, p. 86. 
entendida como discriminación ${ }^{8}$. Es por esto que la sociedad debe realizar y promover políticas públicas y actitudes que ayuden a eliminar las barreras que enfrentan las personas con discapacidad. En ese sentido, la no discriminación de las personas con discapacidad no involucrará únicamente la abstención estatal de generar impedimentos, sino que también requerirá que el Estado tome las medidas pertinentes para lograr la inclusión social de las personas con discapacidad ${ }^{9}$. En razón de lo anterior, es necesario que los Estados reformulen sus políticas públicas para que estas puedan alcanzar efectivamente las necesidades de las personas con discapacidad ${ }^{10}$.

\section{El derecho a la participación política de las personas con discapacidad}

La participación activa del ser humano en los diversos aspectos que involucra la vida en sociedad -en un contexto democrático, claro está- presupone la facultad del mismo de participar en asuntos de índole económica, social, cultural y, evidentemente, política. En tal sentido, podemos definir, a grandes rasgos, al derecho a la participación política, como aquel derecho que nos asiste para tomar parte en la formulación e implementación de decisiones y acciones que conciernen a nuestros intereses y, cuyo sustrato último no es otro que el reconocimiento inherente de nuestra dignidad, en tanto seres humanos. Esto es vinculable con una de las capacidades centrales señaladas por Nussbaum: el control político sobre nuestro propio entorno ${ }^{11}$.

En cuanto a su configuración normativa, el derecho a la participación política se encuentra expresamente reconocido como un derecho fundamental en nuestra Constitución (Artículo $2^{\circ}$ inciso 17 y Artículo $31^{\circ}$ ) y consagrado en diversos instrumentos y tratados internacionales, los cuales integran el denominado bloque de constitucionalidad, como parámetro de regulación e interpretación de los mismos. Respecto de la normativa internacional, es pertinente mencionar el Artículo $21^{\circ}$ de la Declaración Universal de los Derechos Humanos, el Artículo XX de la Declaración Americana de los Derechos y Deberes del Hombre, el Artículo $23^{\circ}$ de la Convención Americana sobre Derechos Humanos y el Artículo $25^{\circ}$ del Pacto Internacional de

8 Bregaglio, Renata, Alcances del mandato de no discriminación en la Convención sobre los derechos de las personas con discapacidad. En: Bregaglio, Renata y Salmon, Elizabeth (coord.). Nueve conceptos claves para entender la Convención sobre los Derechos de las Personas con Discapacidad, IDEHPUCP, Lima, 2015, p. 88.

9 Corte Interamericana de Derechos Humanos. Caso Furlán y Familiares v. Argentina. Excepciones Preliminares, Fondo, Reparaciones y Costas. Sentencia de 31 de agosto de 2012. Serie C 246, párr. 134.

CDPD. Artículo 4.c "Tener en cuenta, en todas las políticas y todos los programas, la protección y promoción de los derechos humanos de las personas con discapacidad". 
Participación es inclusión: El derecho a la participación política de personas con discapacidad

Derechos Civiles y Políticos. De una lectura de los mismos, podemos concluir que, en líneas generales, son la Declaración Universal de los Derechos Humanos y el Pacto Internacional de Derechos Civiles y Políticos los instrumentos normativos que nos otorgan un mayor alcance en la delimitación de los derechos que conforman el contenido del derecho a la participación política, siendo estos: 1) el derecho a participar, ya sea directa o indirectamente en el gobierno de un país 2) el derecho a acceder a la función pública en condiciones de igualdad y 3 ) el derecho a votar y a ser elegido en elecciones auténticas, periódicas y bajo la modalidad del sufragio universal e igual y, del secretismo del voto. Adicionalmente el Pacto Internacional de Derechos Civiles y Políticos, detalla que estos derechos se ejercen "sin ninguna de las distinciones mencionadas en el artículo $2^{\circ}, y$ sin restricciones indebidas", ello en evidente alusión al mandato de igualdad y no discriminación, acotación que deseamos destacar.

Ahora bien, advertimos que, la formulación- acaso formal- del derecho a la participación política presenta una perspectiva especial si la abordamos desde el enfoque que nos ofrece el modelo social de la discapacidad. En tal sentido, se inserta el Artículo $29^{\circ}$ de la Convención sobre los Derechos de las Personas con Discapacidad $^{12}$, que consagra el derecho de las personas con discapacidad de

12 Artículo 29. Participación en la vida política y pública Los Estados Partes garantizarán a las personas con discapacidad los derechos políticos y la posibilidad de gozar de ellos en igualdad de condiciones con las demás y se comprometerán a:

a) Asegurar que las personas con discapacidad puedan participar plena y efectivamente en la vida política y pública en igualdad de condiciones con las demás, directamente o a través de representantes libremente elegidos, incluidos el derecho y la posibilidad de las personas con discapacidad a votar y ser elegidas, entre otras formas mediante:

i) La garantía de que los procedimientos, instalaciones y materiales electorales sean adecuados, accesibles y fáciles de entender y utilizar;

ii) La protección del derecho de las personas con discapacidad a emitir su voto en secreto en elecciones y referéndum públicos sin intimidación, y a presentarse efectivamente como candidatas en las elecciones, ejercer cargos y desempeñar cualquier función pública a todos los niveles de gobierno, facilitando el uso de nuevas tecnologías y tecnologías de apoyo cuando proceda;

iii) La garantía de la libre expresión de la voluntad de las personas con discapacidad como electores y a este fin, cuando sea necesario y a petición de ellas, permitir que una persona de su elección les preste asistencia para votar;

b) Promover activamente un entorno en el que las personas con discapacidad puedan participar plena y efectivamente en la dirección de los asuntos públicos, sin discriminación y en igualdad de condiciones con las demás, y fomentar su participación en los asuntos públicos y, entre otras cosas:

i) Su participación en organizaciones y asociaciones no gubernamentales relacionadas con la vida pública y política del país, incluidas las actividades y la administración de los partidos políticos; 
participar en la vida política y pública, reconociéndoseles no solo el ejercicio de los derechos arriba enunciados (con observancia de los ajustes razonables y la asistencia requeridas para su ejecución), sino también del ejercicio del derecho a participar en organizaciones de personas con discapacidad, tanto gubernamentales como no gubernamentales. Esto último está directamente relacionado con una de las obligaciones generales de los Estados parte de la CDPD, la obligación de consultar. En tal sentido, podemos decir que el derecho a la participación política de las personas con discapacidad consta de cuatro derechos:

- el derecho a sufragar

- el derecho de acceso a la función pública

- el derecho a ser representante político

- el derecho a formar organizaciones que puedan participar en procesos de consulta

\subsection{El derecho al voto o el derecho al sufragio}

El derecho al voto se encuentra consagrado en diversas normas nacionales (artículo 31 de la Constitución Política del Perú, en el artículo 12.2 de la Ley 29973) e internacionales (artículo 21 de la Declaración Universal de los Derechos Humanos (Declaración Universal de los Derechos Humanos); asimismo en el artículo 29.a) de la Convención sobre los derechos de las personas con discapacidad (CDPD) y artículo 23 de la Convención Americana de Derechos Humanos).

El voto debe garantizar la libertad de expresión de la voluntad de los electores, para ellos se debe garantizar el acceso en igualdad de condiciones. En ese sentido, es importante resaltar que, a la luz del artículo 12 de la Convención sobre los Derechos de las Personas con Discapacidad (CDPCD), se reconoce a las personas con discapacidad el ejercicio de capacidad jurídica "en igualdad de condiciones y en todos los aspectos de la vida de las personas" ${ }^{\prime \prime 13}$. En este sentido, la norma incluye la participación en la vida política manifestada en el derecho al voto. Ello en consonancia, a su vez, con el artículo 29 de la CDPCD que dispone que:

"Los Estados Partes garantizarán a las personas con discapacidad los derechos políticos y la posibilidad de gozar de ellos en igualdad de condiciones con las demás y se comprometerán asegurar que las personas con discapacidad puedan participar plena y efectivamente en la vida

ii) La constitución de organizaciones de personas con discapacidad que representen a estas personas a nivel internacional, nacional, regional y local, y su incorporación a dichas organizaciones.

13 Convención de la ONU sobre los Derechos de la persona con discapacidad y su Protocolo Facultativo; instrumentos suscritos el 30 de marzo de 2007, y ratificados el 30 de enero de 2008 por el Estado peruano. 
Participación es inclusión: El derecho a la participación política de personas con discapacidad

política y pública en igualdad de condiciones con las demás, directamente o a través de representantes libremente elegidos, incluidos el derecho y la posibilidad de las personas con discapacidad a votar y ser elegidas".

El ejercicio del derecho al sufragio es un aspecto importante en las vidas de las personas con discapacidad, debido a que han sido excluidas del mismo durante mucho tiempo. En algunos casos, la exclusión ha sido formal, como los impedimentos legales para votar; mientras en otros casos ha sido por la falta de accesibilidad para ejercer el voto.

Con respecto a los impedimentos formales, cabe destacar las consideraciones que emplea el Tribunal Europeo de Derechos Humanos en materia del derecho al voto de personas con discapacidad, por ejemplo, en el caso Alajos Kiss v. Hungría. En este caso, el Tribunal concluye que "la privación indiscriminada del derecho al voto no puede justificarse formalmente sobre la existencia de una incapacitación a menos que en dicho procedimiento del tribunal nacional haya sospechado y probado que la persona se encuentra razonablemente limitada para ejercer su derecho al voto"14.

En esa misma línea, el Comité de los Derechos sobre las Personas con Discapacidad de Naciones Unidas, ha señalado en el caso Zsolt Bujdosó and five others v. Hungary ${ }^{15}$ que el Estado violó el derecho al voto a 6 personas con discapacidad mental e intelectual porque eliminó sus nombres del registro electoral al ser puestos bajo tutela de acuerdo con la Constitución, y como resultado se les había negado el derecho a votar en las elecciones parlamentarias y municipales de 2010, violando los artículos 29 y 12 de la CDPD. El Comité hace hincapié en que a pesar de una norma constitucional dispone los supuestos de inhabilitación al ejercicio de la ciudadanía, no puede impedir el ejercicio del derecho al voto, debido a que este derecho implica el reconocimiento a la igualdad en el ejercicio de la capacidad jurídica como garantía de acceso al goce y ejercicio de otros derechos fundamentales. Finalmente, cabe mencionar el dictamen del Procurador General de Argentina sobre el caso H.O. ${ }^{16}$, quien mediante su curadora pública, solicita su inclusión al padrón electoral a los efectos de quedar habilitado para emitir su sufragio. La pretensión fue sistemáticamente rechazada por la declaración civil de incapacidad que pesaba sobre esta persona. Al respecto, el Procurador señaló:

14 Tribunal Europeo de Derechos Humanos. Caso Alajo Kiss v. Hungría. Application 38832/06. Sentencia del 20 de mayo de 2010.

15 Comité CDPD. Caso Zsolt Bujdosó and five others V. Hungary. Communication 4/2011, 20 de setiembre de 2013, párr. 10.

16

CIV 83563/1997/CS1, "F, H O si artículo 152 ter. Código Civil". Accesible en: http://www.fiscales.gob.ar/procuracion-general/wp-

content/uploads/sites/9/2016/04/CIV 835631997 F.pdf (última fecha de consulta: 30 de octubre de 2016). 


\begin{abstract}
"(...) las personas con discapacidad mental han sido objeto de una exclusión sistemática del cuerpo electoral y la discapacidad mental ha sido considerada históricamente como un factor determinante para negar el ejercicio de la ciudadanía política. Esta exclusión tiene un doble aspecto pues afecta a quienes resultan marginados pero también la pueblo en su conjunto, debilitando la representación y la plena participación de las personas con discapacidad mental en el proceso electoral".
\end{abstract}

De esta manera, el Dictamen reafirmo la importancia de explicitar por qué la interdicción como restricción no resulta beneficiosa para las personas con discapacidad, y resaltó la importancia de conlleva el reconocimiento de la capacidad jurídica de las personas con discapacidad, puesto que les permite ejercer válidamente su derecho al voto. Esto nos permite concluir que, en nuestro país es necesario reformar el artículo 33 de la Constitución que señala que pierden la ciudadanía quienes son sometidos a sentencia de interdicción ${ }^{17}$. Esto genera que las personas con discapacidad intelectual o psicosocial pierdan su derecho a votar o postular a un cargo público. Ello es contrario a la Convención y por tanto es necesario derogar dicho inciso.

Por otro lado, el derecho al sufragio se enfrenta a distintas barreras físicas, entre ellas la falta de accesibilidad que conlleva la vulneración de otros derechos fundamentales. Por ejemplo, en el último proceso electoral, el ciudadano José Antonio Ísola, persona con discapacidad y usuario de silla de ruedas "concurrió a cumplir con su deber de votar, $y$, una vez más, se encontró con un sistema excluyente que no le permitió emitir su voto debido a que su mesa de votación se encontraba en un segundo piso. La solución brindada por los organismos electorales, la entrega de una constancia, le obligaba a tramitar personalmente una dispensa frente a un sistema lleno de barreras y limitaciones al ejercicio de derechos $(. . .)^{n 18}$. Este ejemplo nos demuestra la situación que enfrentan las personas con discapacidad en el Perú para poder ejercer su derecho al sufragio y ejemplifica un escenario dónde se vulnera la capacidad jurídica de goce, como de ejercicio. En el caso del señor Ísola, el referido suceso ha generado una vulneración de sus derechos. Por todo esto, resulta necesario que se garanticen las medidas de accesibilidad necesarias para que el sufragio sea una realidad para todos ${ }^{19}$

17 Artículo 33.- El ejercicio de la ciudadanía se suspende:

1. Por resolución judicial de interdicción. (...)

Asociación Pro Derechos Humanos (APRODEH). Notas de prensa APRODEH. Publicado el 17 de junio del 2016. Disponible en: http://www.aprodeh.org.pe/index.php/sala-deprensa/notas-de-prensa/entry/poblacion-con-discapacidad-felicita-a-kuczynski-y-renuevaesperanzas-de-lograr-mayor-inclusion-en-el-proximo-gobierno (última fecha de consulta: 30 de octubre de 2016).

19 Al respecto, ver Comité Sobre Derechos De Las Personas Con Discapacidad. Examen de los informes presentados por los Estados partes en virtud el artículo 35 de la Convención. 
Participación es inclusión: El derecho a la participación política de personas con discapacidad

y también se requiere que se reformen "las leyes pertinentes de manera que todas las personas con discapacidad puedan disfrutar del derecho a votar y a presentarse a las elecciones, independientemente de que estén sometidas a tutela u otros regímenes" ${ }^{20}$.

\subsection{El derecho de acceso a la función pública}

El derecho al acceso a la función pública, es también parte fundamental del contenido del derecho a la participación política. Ello, en tanto se reconoce a este último, un carácter $\mathrm{o}$ aspecto funcional; en la medida en que se encuentra estrechamente vinculado al ejercicio de la función pública, aunque no solo se restringe a ella ${ }^{21}$.

En buena cuenta, conceptos tales como la democracia (en un contexto de libertad, igualdad y respeto de los derechos fundamentales) y el propio acceso a la función pública, no pueden ser ajenos al derecho a la participación política, toda vez que, entendemos la importancia que este derecho posee en la legitimación de la configuración del Estado en su dimensión política y, en los distintos niveles de gobierno en que ello pudiera repercutir.

Ahora bien, en materia de discapacidad, que es a lo que a nosotros atañe, hemos de advertir que existe un deber del Estado de garantizar y asegurar, en los términos del Artículo $29^{\circ}$ de la Convención sobre los Derechos de las Personas con Discapacidad, que las personas que presenten una situación de discapacidad puedan participar plena, efectivamente y en igualdad de condiciones, en la vida política y pública y; más aún, el referido tratado les reconoce, de forma expresa, el derecho a : (...) presentarse efectivamente como candidatas en las elecciones, ejercer cargos y desempeñar cualquier función pública a todos los niveles de gobierno, facilitando el uso de nuevas tecnologías y tecnologías de apoyo cuando proceda $(. . .)^{22}$.

Resulta indubitable, por tanto, al margen del concepto, acaso más o menos amplio, que de la función pública podamos concebir, que las personas con discapacidad poseen el derecho y el Estado el deber, de asegurar y garantizar el derecho de acceso

Sexto periodo de sesiones. Disponible en:
www.ohchr.org/Documents/HRBodies/CRPD/6thsession/CRPD.C.ESP.CO.1 sp.doc (última fecha de consulta: 30 de octubre de 2016).

20 Observaciones finales sobre el Informe Inicial de la República Checa, aprobadas por el Comité en su $13^{\circ}$ período de sesiones ( 25 de marzo al 17 de abril de 2015). República Checa: CRPD/C/CZE/CO/1 numeral 58.

21 Boyer Carrera, Janeyri, "Aproximaciones al contenido esencial del derecho a la participación política". En: Pensamiento Constitucional, Año XIII, n. 13, Lima, 2008, p. 367.

22 Artículo 29 a) ii) de la Convención sobre los Derechos de las personas con Discapacidad. Subrayado nuestro. 
a la función pública en favor de aquellas, por ser parte de la denominada vida política de la nación. El ejercicio efectivo de este derecho; debe darse, además, en un contexto de igualdad, respecto de aquellas personas que no presentan una situación de discapacidad; es decir, aquellas que no encuentran una barrera social particular que suponga un límite, para la plena realización de sus derechos, en este caso, políticos.

Pese a ello, el derecho al acceso a la función pública, al igual que ocurre en el caso del derecho al acceso y permanencia en el trabajo (al cual se haya también vinculado) presenta, en el contexto de nuestra sociedad, un desarrollo aún incipiente, además de afrontar considerables déficits en cuanto a su concreción. En tal sentido, advertimos que, el derecho al acceso a la función pública afronta, en la actualidad, barreras de variada naturaleza, tal y como evidencia el precedente judicial sentado en el caso del Señor Edwin Béjar (Expediente 2009-01890-0-1001-JR-CI-3), en el proceso de amparo que siguiera contra el Consejo Nacional de la Magistratura (CNM).

Como obra de los hechos de esta sentencia, tenemos que el demandante interpuso una demanda de amparo contra el CNM ya que, tras postular a la Plaza de Fiscal Adjunto Provincial de Cuzco, declarando su situación de discapacidad y, siendo, además, declarado apto para la realización del examen de selección (para lo cual solicitó de forma oportuna el apoyo requerido) se le comunicó que sería impedido de rendir la referida evaluación, hecho que en efecto sucedió, al presentarse el demandante a rendir la evaluación y verse impedido de hacerlo.

El tribunal, en tal sentido, procedió a dilucidar si con este trato se había incurrido o no en una situación de discriminación, bajo tal entendido, analizó la legitimidad del impedimento ejercido por el CNM, dado en virtud del Acuerdo de Sesión Plenaria Ordinaria del CNM (Informe 067-2009-CPSN-CNM), que concluyó la denegatoria al demandante para rendir el examen, basándose en el Artículo 4 numeral 6) de la Ley de la Carrera Judicial (Ley 29277), norma que se encontraba vigente al momento de dilucidarse la causa y arguyendo, de forma adicional que, al requerirse la ayuda de una tercera persona para realizar el examen, este ya no sería de carácter "personal"23.

El tribunal advirtió, como no escapa a un juicio de razonabilidad que, solicitar apoyo no en la resolución sino en la dación del examen (marcar las opciones múltiples) no suponía que la evaluación perdiera su cualidad de ser personal, además se destacó que el propio demandante propuso opciones alternativas de solución, como, por ejemplo, la realización de la prueba mediante un software especial.

Es importante destacar, llegado a este punto que, llama a la reflexión la opinión, sostenida por la parte demandante, según la cual existiría un impedimento, de ser el

23 Estos sucesos fueron precisados en el Décimo Primero y Décimo Sexto considerandos de la sentencia recaída en el Expediente 2009-01890-0-1001-JR-CI-3. 
Participación es inclusión: El derecho a la participación política de personas con discapacidad

demandante elegido magistrado, para que este realice labores de "mayor importancia" que supondrían el ejercicio propio de su cargo, en tanto fiscal. Frente a ello, la sentencia destacó que no resultaba razonable descalificar al postulante solo por considerar que existen funciones de mayor importancia que este-presuntamente - no podría realizar, más aun, sostuvo que, de ser elegido, correspondería al propio empleador, brindarle al demandante las facilidades para desempeñar sus funciones, además de asignarle las responsabilidades que le competan, conforme a la capacidad profesional que este detenta, a tenor de no vulnerar el derecho a la no discriminación por motivo de discapacidad, entre otros derechos de observancia constitucional.

Es así que, si bien en casos como el del funcionario Béjar, en el que el acceso a la función pública fue debidamente tutelado por el legislador, no podemos afirmar que exista una plena incorporación de las personas con discapacidad en el ámbito de la participación política, en nuestro país. Más aun, la integración de las personas con discapacidad ha sido mínima y, se encuentra reducida en contados casos; esencialmente, a aquellos supuestos de personas que presentan una discapacidad o limitación social de naturaleza física y/o sensorial; encontrándose barreras incluso frente a tales supuestos, mismas que ya debieran haber sido superadas, como evidencia el caso objeto de análisis, en el que advertimos desde ya, la existencia de prejuicios, respecto de la pretendida falta de capacidad que tendrían personas como el demandante, para ejercer sus funciones o labores, con autonomía y a la par que el resto de personas o servidores públicos. De hecho, la actual Ley de Servicio Civil señala que para que una persona pueda ingresar a la función pública, debe estar en pleno uso de sus derechos civiles lo que nuevamente excluye a las personas con discapacidad que están sometidas a un proceso de interdicción.

Concluimos por todo ello que, existe aún un largo camino por recorrer si deseamos, cuanto menos, equiparar las condiciones en las que las personas con discapacidadcualesquiera que esta sea (física, sensorial, mental o psicosocial) - participan como parte activa de la vida política de nuestra nación; concretamente en el acceso a la función pública y que, se garantice que las mismas no solo puedan acceder al ejercicio de estas funciones, en las mismas condiciones que las demás personas, sino que puedan permanecer en el ejercicio de sus cargos de manera sostenida y garantizándose además su plena autonomía.

\subsection{El derecho a la representación política}

El derecho a la representación política, como sabemos, forma parte del contenido esencial del derecho a la participación política, contenido en el Artículo 29 de la CPCD. Es así que, mediante este derecho se reconoce, como fuera ya mencionado, el derecho a la participación política en su dimensión activa, es decir, en la capacidad de ejercer cargos de representación política $y$, por ende, ser susceptibles, no solo de elegir sino de ser elegidos válidamente. A nivel jurisprudencial, la sentencia del caso Yatama $v$. 
Nicaragua ${ }^{24}$, la Corte Interamericana de Derechos Humanos hace alusión a este derecho:

"La participación política puede incluir amplias y diversas actividades que las personas realizan individualmente $u$ organizados, con el propósito de intervenir en la designación de quienes gobernarán un Estado o se encargarán de la dirección de los asuntos públicos, así como el influir en la formación de la política estatal a través de mecanismos de participación $\operatorname{directa}^{25}(\ldots)$ La participación mediante el ejercicio del derecho a ser elegido supone que los ciudadanos puedan postularse como candidatos en condiciones de igualdad y que puedan ocupar los cargos públicos sujetos a elección $(\ldots)^{126}$.

En atención a ello, podemos entender que, en primer término, el derecho a la representación política supone un actuar directo y activo de los individuos (ya sea en asociación o de forma particular) para formar parte de la vida política y pública de la nación, que tiene como presupuesto que esta se de en condiciones de igualdad y; claro está, en observancia de las condiciones de legitimidad propias del proceso de elección en el que se participe. Ahora bien, la citada jurisprudencia del caso Yatama resulta especialmente relevante por implicar el pronunciamiento de la Corte respecto del derecho a la participación política de las comunidades indígenas y nativas (en este caso, del Caribe Nicaragüense) reconociéndose el derecho de manifestar, en condiciones de igualdad, su libre determinación política y organizativa. Esto es importante pues, la configuración del derecho a la participación política se dio en relación a un colectivo, cuya situación de especial vulnerabilidad fue destacada por el Tribunal, en la medida que la preservación de sus costumbres suponía, en última instancia, la existencia misma de su cultura. Ahora bien, advertimos que, la situación de vulnerabilidad de un determinado colectivo o grupo de personas que comparten características comunes que las sitúan en una condición de desigualdad social, por ejemplo, el caso de las comunidades indígenas o nativas, mujeres y personas con discapacidad; merecen una especial tutela, precisamente, para lograr que esas condiciones de igualdad puedan verse satisfechas. Las personas con discapacidad han

$24 \quad$ El referido caso se originó con la denuncia interpuesta contra el Estado de Nicaragua, en la que se alegara la vulneración de diversos Arts. de la Convención Americana sobre Derechos Humanos $\left(1^{\circ} .1,23^{\circ}\right.$ y $25^{\circ}$, entre otros), en perjuicio de los candidatos a alcaldes, vicealcaldes y concejales presentados por el partido político regional indígena "Yatama", al excluírseles de participar en las elecciones municipales del año 2000, en las Regiones Autónomas del Atlántico Norte y del Atlántico Sur, a causa de las decisiones es emitidas por el Consejo Supremo Electoral del Nicaragua. (Numeral 2 de la sentencia Yatama v. Nicaragua).

Numeral 196 de la sentencia del caso Yatama v. Nicaragua.

Numeral 199 de la sentencia del caso Yatama v. Nicaragua. 
Participación es inclusión: El derecho a la participación política de personas con discapacidad

sido excluidas e invisibilizadas en nuestras sociedades ${ }^{27}$. Tal exclusión ha tenido un correlato en la representación política. Así, las personas con discapacidad:

"(...) al padecer de discriminación y exclusión social, han estado completamente al margen de la participación política. El ejercicio de sus derechos políticos, como participar en los procesos electorales u organizarse en asociaciones civiles, es un fenómeno incipiente (...). Es muy probable que, si hoy se realizara en los países latinoamericanos una medición de la calidad democrática de participación de ciudadanos y ciudadanas con discapacidad en la gestión pública, los resultados serían muy pobres"28.

Reconocer esto supondrá finalmente, la necesidad de implementar políticas y acciones positivas por parte del Estado — con la participación de la sociedad civil- encaminadas a acortar las referidas brechas; evidenciadas como sabemos, en la desigualdad, acaso estructural que posee también nuestra sociedad, de conformidad con las obligaciones que vinculan al Estado en materia del respeto, la garantía y la promoción de los derechos de las personas con discapacidad. A manera de ejemplo, es posible señalar que en el último Parlamento (2011 - 2016) fueron elegidos únicamente cinco personas con discapacidad (Michael Urtecho, Javier Diez Canseco, Giancarlo Vachelli, John Reynaga y Luis Galarreta), pero en el siguiente solamente habrá uno. En base a lo expuesto, resulta relevante realizar también una comparación con la cuota de género en las elecciones para congresistas o regidoras. En base a la existencia de una minoría vulnerable para nuestra sociedad las mujeres por mucho tiempo han sido excluidas del ámbito político. Ante esta situación, mediante la Ley Orgánica de Elecciones (LOE), Ley 26859, en el artículo 116 se estipula el porcentaje de $30 \%$ para las elecciones de Congresistas de la República, igualmente en la Ley de Elecciones Municipales, Ley 26864, señala en el artículo 10, inciso c); el porcentaje de género (30 \%) para las elecciones municipales. Las cuotas de género en nuestro país son "(...) una medida especial de carácter temporal no como una excepción a la regla de la no discriminación, sino como una estrategia necesaria de los Estados Partes para lograr la igualdad sustantiva o de facto de la mujer y el hombre en el goce de sus derechos humanos y libertades fundamentales (...)"29.

27 Astorga Gatjens, Luis Fernando, "La Consulta a las personas con discapacidad". En: Nueve conceptos claves para entender la Convención sobre los Derechos de las Personas con Discapacidad, 2014, IDEHPUCP, p. 169.

Astorga Gatjens, Luis Fernando, "La Consulta a las personas con discapacidad". En: Nueve conceptos claves para entender la Convención sobre los Derechos de las Personas con Discapacidad, 2014, IDEHPUCP, pp. 176 y ss. 25, sobre el párrafo 1 del artículo 4 de la Convención sobre la eliminación de todas las 
Por tanto, destacamos que, normativamente, las cuotas de género no se encuentran exentas de regulación en nuestro ordenamiento, al existir tanto a nivel del Congreso de la República ${ }^{30}$, a nivel regional ${ }^{31}$ y municipal ${ }^{32}$ o el caso de las denominadas cuotas generacionales y cuotas indígenas dadas en virtud de la Ley $28869^{33}$. Es cierto que estas medidas no han sido del todo efectivas, no obstante, consideramos que es un primer paso que también se requiere en el caso de personas con discapacidad. El Estado debe fomentar una cuota mínima que asegure la participación de las personas con discapacidad en los niveles de gobierno, puesto que quienes asuman la representación de la sociedad civil, constituyen mecanismos para conseguir resultados basados en promover el desarrollo y mejora de las condiciones de vida de las personas de la comunidad. Por tanto, es necesario que el Estado intensifique "sus gestiones para incluir a las personas con discapacidad en los cargos de representación electoral y los cargos públicos" ${ }^{14}$. La cuota sería una de las "medidas para promover el derecho de las personas con discapacidad a presentarse como candidatos cargos de elección popular"135.

En el supuesto de existir una la modalidad de cuotas razonables para las personas con discapacidad, no significa que la representación de los usuarios esté garantizado, puesto que resulta relevante que sean liderados de manera óptima por parte de los partidos políticos y en el supuesto que lleguen a obtener una plaza, no concreta el

formas de discriminación contra la mujer, referente a medidas especiales de carácter temporal. Párrafo 17.

El artículo 116 de la Ley 26859 prevé que las listas de candidatos al Congreso en cada Distrito Electoral deben incluir un número no menor del $30 \%$ de mujeres o de varones y que en las circunscripciones en que se inscriban listas con tres candidatos, por lo menos uno de los candidatos debe ser varón o mujer.

El artículo 12 de la Ley 27683 prevé también la cuota de no menos del 30\% de mujeres o varones en la lista de candidatos al Consejo Regional.

32 El artículo 10 inciso 2 de la Ley 26864, establece que el número correlativo que indique la posición de los candidatos a Regidores en la lista, que debe estar conformada por no menos de un $25 \%$ de hombres o mujeres.

Esta Ley contempla que las listas de regidores tanto regionales como municipales deben estar conformadas por no menos de un $30 \%$ de hombres o mujeres, no menos de un $20 \%$ de ciudadanos jóvenes menores de 29 años y un mínimo de $15 \%$ de representantes de comunidades nativas y pueblos originarios. Artículo 1 de la Ley 28869.

Observaciones finales sobre el Informe Inicial de Serbia, aprobadas por el Comité en su $15^{\circ}$ período de sesiones (29 de marzo a 21 de abril de 2016). Serbia: CRPD/C/SRB/CO/1 numeral 59. su $9^{\circ}$ período de sesiones (15 al 19 de abril de 2013). Paraguay: CRPD/C/PRY/CO/1. 
Participación es inclusión: El derecho a la participación política de personas con discapacidad

debido derecho a la participación política, sino que se efectivizará cuándo ejerzan sus funciones y formen parte de la toma de decisiones.

Concluimos, por tanto, que la situación que atraviesan las personas con discapacidad afronta no solo las limitaciones propias de un legado de olvido e invisibilización social, trasversal a sociedades como la nuestra, sino la falta de iniciativa; en especial, la proveniente del sector público, en donde parece ser un patrón común la no previsión de mecanismos que permitan el acceso de las personas con discapacidad a los cargos públicos y cargos de elección popular, que permita que estas ejerzan plenamente su derecho a la representación política. Este cuadro se agrava si hacemos énfasis en discapacidades de índole intelectual, mental o psicosocial, hecho que el Comité ha destacado ya en reiteradas oportunidades.

\subsection{El derecho a la consulta}

Una de las novedades de la Convención es la obligación de consulta ${ }^{36}$. Esta surge como una forma de compensar la exclusión y se enmarca en la filosofía: "nada sobre nosotros sin nosotros". Ello se vio reflejado en la misma elaboración de la Convención en la que participaron varias organizaciones de personas con discapacidad. No existe aún una única fórmula para aplicar la consulta. Así, el Comité de Personas con Discapacidad a veces ha llamado a la creación de un mecanismo vinculante ${ }^{37}$ o mayor inclusión en los órganos especializados en discapacidad del Estado ${ }^{38}$.

A nivel nacional esto también se ha consagrado. En el artículo 14 de la Ley General de la Persona con Discapacidad (Ley 29973), se menciona el derecho a la consulta, como obligación de las autoridades de los niveles del gobierno para que puedan realizar consultas con las organizaciones que representan a las personas con discapacidad, previamente a la adopción de normas legislativas y administrativas, programas, entre otros. Todos estos procesos de consulta deben ser adoptados en base a los principios

\section{$36 \quad$ Artículo 4.3}

En la elaboración y aplicación de legislación y políticas para hacer efectiva la presente Convención, y en otros procesos de adopción de decisiones sobre cuestiones relacionadas con las personas con discapacidad, los Estados Partes celebrarán consultas estrechas y colaborarán activamente con las personas con discapacidad, incluidos los niños y las niñas con discapacidad, a través de las organizaciones que las representan.

37 Observaciones finales sobre el Informe Inicial de Chile, aprobadas por el Comité en su $15^{\circ}$ período de sesiones ( 29 de marzo a 21 de abril de 2016). Chile CRPD/C/CHL/CO/1, párr. 10. (última fecha de consulta: 30 de octubre de 2016).

Observaciones finales sobre el Informe Inicial de Chile, aprobadas por el Comité, República Dominicana $\mathrm{CRPD} / \mathrm{C} / \mathrm{DOM} / \mathrm{CO} / 1$, párr. 7. (última fecha de consulta: 30 de octubre de 2016). 
de accesibilidad, buena fe, oportunidad y trasparencia. Asimismo, en el Artículo 12 del reglamento de la Ley General de la Persona con Discapacidad se menciona que previamente a la adopción de normas legislativas y administrativas, políticas y programas sobre cuestiones relativas a la discapacidad, éstas deben ser difundidas por un plazo no menor de treinta (30) días, conforme a lo establecido en el Artículo 14 del Decreto Supremo 001-2009-JUS. Lamentablemente, a pesar de la existencia de las normas legales, podemos expresar que, no resulta efectivo en la realidad ni adecuado para las personas con discapacidad (incluidos los niños, niñas y adolescentes) ${ }^{39}$ el mecanismo establecido para efectivizar el derecho de consulta. Este mecanismo no resulta plenamente eficaz por diversos motivos.

El primer obstáculo es la difusión de las normas, programas y políticas, los cuales son pre-publicados en imagen PDF (a través del portal institucional de los ministerios), el contenido de las mismas no resulta accesible para las personas con discapacidad sensorial (por ejemplo, con menoscabo visual o auditivo), mental o intelectual, a menos que cuenten con intérpretes, guías intérpretes y otros medios aumentativos o alternativos que permita la comprensión de la medida.

En segundo lugar, el diálogo entre las entidades públicas, las organizaciones de personas con discapacidad y los usuarios con discapacidad (dotado de una plataforma accesible y medios que faciliten la comunicación con las personas con discapacidad) en el Perú no ha sido implementado de forma satisfactoria. Esta situación se ve evidenciada por datos fácticos, pues, alrededor de 10 millones de personas a nivel nacional se encuentran en situación de pobreza, por lo tanto, un gran número de personas carecen de servicios básicos; entre ellos la luz, otros, a pesar de contar con dichos servicio, carecen de aparatos electrónicos o acceso a Internet, por tanto, las plataformas virtuales son para estas personas constituyen medios inaccesibles.

En tercer lugar, el corto plazo estipulado en el reglamento para que las personas con discapacidad puedan comentar y emitir opiniones jurídicas con su debido consentimiento, en un plazo de 30 días (o de siete días, en el caso del proyecto de reglamento de la Ley 30150) resulta una medida contraproducente. Al respecto, es necesario pensar si, acaso, puede ser considerado razonable, considerando a aquel sector de personas con discapacidad cuya lengua materna no es el castellano, que atraviesa por dificultades de comunicación y accesibilidad y, que habita en lugares alejados de la ciudad capital. De acuerdo, al último Informe de la Defensoría del Pueblo al Congreso de la República de Enero-Diciembre $2014^{40}$, si bien el marco legal

39 El Artículo 13 del Código de Niños y Adolescentes reconoce el derecho de asociación de los adolescentes y la adhesión de los niños a las personas jurídicas sin fines de Lucro. 2014 http://www.defensoria.gob.pe/modules/Downloads/informes/anuales/DecimoctavoInforme-Anual.pdf (última fecha de consulta: 30 de octubre de 2016). 
Participación es inclusión: El derecho a la participación política de personas con discapacidad

garantiza la participación de las personas con discapacidad, en la práctica la implementación del derecho a la consulta viene presentando algunas limitaciones, entre ellas, la omisión total de la consulta, como sucedió en el caso del Reglamento de justificación y dispensa electoral, a pesar de que se aplica a todo tipo de elecciones, referéndum y consulta popular. En este caso no se estableció plazo para que se efectúen sugerencias o comentarios.

A nivel local, advertimos que, a pesar de la existencia del Consejo de Coordinación Local (CCL), es un ente que promueve la participación ciudadana en las materias públicas de gobierno municipal que se fundamenta en el carácter descentralizado del Estado ${ }^{41}$, los espacios de coordinación con CONADIS son muy pocos. Tampoco ha sido adecuadamente aprovechada la estructura legal constituida por SINAPEDIS (Sistema Nacional de la Persona con Discapacidad) en donde el Consejo Nacional para la Integración de la Persona con Discapacidad (CONADIS) debería coordinar con sus similares de nivel regional (OREDIS) y local (OMAPED).

\section{Conclusiones}

- Mediante el modelo social planteado por la Convención sobre los Derechos de las Personas con Discapacidad se pretende borrar las barreras sociales que impide que los usuarios con discapacidad como un colectivo vulnerable sean reconocidos como sujetos que puedan ejercen plenamente su capacidad jurídica que se verá plasmado en la realización de sus derechos, entre ellos, el derecho a la participación política y a la consulta.

- En el Perú, las instituciones encargadas de efectivizar el derecho a la participación política son entes que a lo largo del tiempo demuestran ser inestables e ineficaces, debido a que medios que emplean no son accesibles para todos los usuarios de discapacidad $y$, por lo tanto, no son incluidas de manera efectiva en la toma de decisiones.

- En ese sentido, a pesar de la existencia del CONADIS y el Consejo de Coordinación Local Distrital no garantizan a las personas con discapacidad sus derechos como ciudadanos. Ante ello, nos parece sumamente importante reforzar el derecho a la consulta, mediante un nuevo órgano que incluya a la sociedad civil, las organizaciones y a las personas con discapacidad para efectivizar plenamente el derecho a la participación política en todas sus dimensiones. De esa manera, no solo se reducen las barreras sociales impulsadas por nuestra sociedad, sino que además, se efectiviza una verdadera participación democrática.

41 Pamelhy Valle, Maritza, Pauca Suquilanda, Fiorella, et. al. El derecho de las personas con discapacidad (PCD) a la participación ciudadana en la adopción de decisiones de las municipalidades locales. [monografía], 2016, p.12. 
- Las personas con discapacidad han sido históricamente excluidas de participar tanto en la vida política como publica, es decir de gozar, en igualdad de condiciones de un entramado de derechos de índole política (sufragio, en su acepción activa y pasiva, derechos de representación, consulta, entre otros) en igualdad de condiciones con las demás. En tal sentido, opciones como la cuota política, podrían ser herramientas útiles.

- Asimismo, respecto de la participación en organizaciones o asociaciones de personas con discapacidad, la participación de estas es aún incipiente, por lo que se requiere promover, a través de iniciativas tanto públicas (cuotas por motivo de discapacidad, por ejemplo) como privadas la inclusión de estas personas de manera tal que se asegure su participación plena y desarrollo autónomo en ámbitos como el de la participación política.

- Finalmente, la nueva figura de la consulta aún no ha sido plenamente aplicada. Han existido muchas barreras a su aplicación pero es necesario insistir en ella pues permite que las personas con discapacidad incidan efectivamente en las políticas públicas que el Estado plantea para ellas. 